\title{
Economic Psychology and Fashion Marketing Theory: Appraising Veblen's Theory of Conspicuous Consumption
}

\author{
Arch G. Woodside, Boston College \\ Pre-publication version of reference: Woodside, Arch G. 2012. Economic Psychology and \\ Fashion Marketing theory Appraising Veblen's Theory of Conspicuous Consumption, Journal of \\ Global Fashion Marketing, 3 (2): 55-60.
}

Send correspondence to Arch G. Woodside, Boston College, Carroll School of Management, Department of Marketing, 140 Commonwealth Avenue, Chestnut Hill, MA 02467, USA; telephone/fax: +1 617552 3069/6677. 


\title{
Economic Psychology and Fashion Marketing Theory Appraising Veblen's Theory of Conspicuous Consumption
}

\begin{abstract}
The study here serves to examine customer choice and firm profitability outcomes from the conjoining of four perspectives: economics, fashion, marketing, and psychology. This article describes core tenets of fashion marketing theory (FMT) from the perspective of economic psychology. The study here is unique and valuable in proposing empirically testable hypotheses that follow from FMT and in describing evidence from available literature testing these hypotheses. The core tenets reflect the view that impactful fashion marketing moderates the relationships among price and consumer demand for the firm's offering (i.e., brand) by psychological customer segments, and subsequently firm profitability. Relating to fashion marketing, "psychology" in "economic psychology" includes the influences of chronic desire for conspicuous consumption (CC) and desire for rarity as relative human conditions, that is, humans vary in these desires; consumers relatively very high versus very low in these desires are more prone to enact conspicuous choices whatever the price level of the object or service. Consequently, different pricing points (decisions) that maximize profitability vary considerably for product designs which are positioned high in $\mathrm{CC}$ and rarity directed to customers very high in chronic desire for $\mathrm{CC}$ and rarity versus product designs which are positioned low in $\mathrm{CC}$ and rarity directed to customers very low in chronic desire for $\mathrm{CC}$ and rarity.
\end{abstract}

Keywords: choice; customer; economic; fashion; marketing; profitability; psychology 


\title{
Economic Psychology and Fashion Marketing Theory Appraising Veblen's Theory of Conspicuous Consumption
}

\author{
Without reflection or analysis, we feel that what is inexpensive is \\ unworthy. "A cheap coat makes a cheap man." "Cheap and nasty" \\ is recognized to hold true in dress with even less mitigation than in \\ other lines of consumption. Veblen (1899, p. 170)
}

Veblen (1899, p. 169) expands on the theme that dress is central to conspicuous consumption, "It is true of dress in even a higher degree than of most other items of consumption, that people will undergo a very considerable degree of privation in the comforts or the necessaries of life in order to afford what is considered a decent amount of wasteful consumption; so that it is by no means an uncommon occurrence, in an inclement climate, for people to go ill clad in order to appear well dressed." Veblen's views are worth noting for several reasons, especially in setting forth the proposition that while "cheap" goes with "nasty" so to "expensive" goes with "pleasant" and "pleasing." His views on conspicuous consumption (CC) frequently include the expression, "conspicuous waste," to indicate the tendency to pay more than necessary for an item suitable to a need or want to indicate exceptional status and good taste to others.

Veblen conjoins economic concepts of price with psychological concepts of perception, status, and reputation. "By further habituation to an appreciative perception of the marks of expensiveness in goods, and by habitually identifying beauty with reputability, it comes about that a beautiful article which is not expensive is accounted not beautiful" (Veblen, 1899, 133).

Figure 1 provides multiple-discipline propositions that relate price, demand (choice), design, chronic desire, and/or perception. For the fashion marketing perspective in Figure 1, 
Berger and Ward (2010) describe such an inverted relationship between brand logo visibility in marketing images and price. They report that regressing brand identification on price and price squared indicates that, while brand identification increased with price $(\mathrm{B}=.0088, \mathrm{SE}=0034, \mathrm{p}=$ $.008)$, it was negatively related to price squared $(\mathrm{B}=-.0014, \mathrm{SE}=.0005, \mathrm{p}=.006)$. While only $21 \%$ of sunglasses under $\$ 50$ contained a brand name or logo, for example, this increased to $84 \%$ among sunglasses between $\$ 100$ and $\$ 300$. But as price increased further, explicit branding decreased: among sunglasses priced more than $\$ 500$, for example, only $30 \%$ displayed a brand name or logo. The same pattern holds in a similar analysis of handbags. While cheaper bags (i.e., those under \$100) had few logos or brand-related patterns and mid-priced bags (i.e., \$200-\$300) often contained brand identifiers, signal explicitness decreased among higher-priced bags. Bags more than $\$ 600$, for example, had comparable values of signal explicitness to the cheapest bags. See Berger and Ward (2010) for further details.

Figure 1 here.

The discussion here attempts to make two points. First, different disciplines bring valuable and unique perspectives to fashion marketing. Second, nuances exist in such conjoining of perspectives. For example, taking into account chronic desires by consumers with manipulated brand designs and price are necessary to achieve sufficiency in explaining consumers' marketplace responses to fashion alternatives.

Berger and Ward (2010) describe the nuanced-view in fashion marketing in the following conclusion to their study. When high-end products used less explicit brand identification most people thought they were equivalent to much cheaper low-end alternatives. However, even 
though more subtle signs are harder to identify, insiders preferred them. This is driven by insiders' desire to distinguish themselves from mainstream consumers who prefer products with explicit brand identification that are more readily identifiable by most observers. Insiders, however, prefer subtler options that are only decodable by others in the know. Further, underscoring the notion that these effects are driven by identity signaling and outward communication, they are stronger in identity-relevant product domains and when consumption was publicly visible.

The present study contributes to theory by building from Veblen's (1899) views that CC includes wearing expensive fashionable clothing and from the benefits of applying multidiscipline perspectives to achieve a nuanced-view of fashion-marketing's impact. The study proposes a series of testable tenets that follow from the view that not all consumers respond the same to clothing alternatives positioned to reflect high versus low CC. Empirical evidence from a literature review supports the core tenets of the theory. The theory supports the normative view that different price points are acceptable for consumers high versus low in $\mathrm{CC}$;

consequently, customer choices and firm profits will vary considerably from the match and missmatch of high versus low $\mathrm{CC}$ strategies and customer chronic levels of $\mathrm{CC}$ at different price points.

\section{The Theory of Chronic and Manipulated Conspicuous Consumption, Price, Customer Choice, and Firm Profitability}

The theory includes the following tenets. (1) Consumers vary in their chronic desire-forCC. (2) Consumers relatively highest versus lowest in chronic desire-for-CC more frequently select brands positioned to be high versus low in CC. (3) Consumers vary in their chronic desirefor-uniqueness (e.g., desire-to-achieve rare acquisitions). (4) Consumers relatively highest 
versus lowest in chronic desire-for-uniqueness more frequently select brands positioned to be high versus low in uniqueness. (5) The negative impact of price increases on choice is lowest for the brand positioned as delivering high CC among consumers highest versus lowest in chronic CC. (6) The negative impact of price increases on choice is highest for a brand positioned as delivering low $\mathrm{CC}$ among consumers high versus low in chronic $\mathrm{CC}$.

(7) The most profitable price points vary by different combinations of chronic CC and manipulated $\mathrm{CC}$ whereby a very high price is most profitable for the highest-chronic $\mathrm{CC}$ when coupled with manipulated high CC; a moderate price point is most profitable for a lowestchronic CC coupled with manipulated high CC; and a low price point is most profitable for a lowest-chronic CC when coupled with a manipulated high CC (curve d-e-f in Figure 2); a profitable outcome occurs for a low price point for the combination of lowest chronic $\mathrm{CC}$ or rarity, manipulated low CC or rarity, and lowest price (demand curve g-h-i in Figure 2). (8) Demand is so low for all three price points among the highest chronic desire for CC or rarity coupled with manipulated low CC or rarity, that no price point is profitable (demand curve j-k-1 in Figure 2); such consumers are vigilant about avoiding low CC or rarity items even when the items are available at bargain prices.

Figure 2 here.

Figure 2 is a visual of the impacts of the various combinations of chronic $\mathrm{CC}$ and manipulated CC at various price points. Note that the theory predicts that choice is greatest for the highest chronic $\mathrm{CC}$ (or highest chronic rarity) consumers in combination with manipulated 
high CC (or rarity) at all three price points (specific prices would be used in a laboratory or field experiment to test this hypothesis).

The impact of price on choice is modest and indicates an inverse curvilinear relationship for the highest chronic conditions and manipulated high $\mathrm{CC}$ or high rarity-refer to line covering points $\mathrm{a}, \mathrm{b}$, and $\mathrm{c}$ in Figure 2. One rationale for this hypothesis is that chronic highest CCs are vigilant, ever watchful, for responding to high $\mathrm{CC}$ or high rarity fashion opportunities and within reason, they expect-to-pay high versus low prices for such purchases - thus Figure 2 includes the a-to-b increase in demand for the increase in price and only a modest decrease in demand for a further substantial increase in price (b-to-c). This a-b-c visual represents Veblen's dictum that high $\mathrm{CC}$ is a recipe that includes high quality, high visibility, and high price with the additional ingredient that highest chronic CC consumers are willing-to-pay a high premium for such items.

Figure 3 represent the ninth explicit statement in the theory and extends the findings that Eskin (1975) reports for convenience food products. (9) For high-end fashion products about the same peak profits are possible with low, moderate, and high prices depending on the recipe of customer segments and fashion marketing designs at each price point. The high-end fashion marketer needs to take care to include the low price in the product design and communication recipe for the price sensitive customer and the high price in the product design and communication recipe for the price insensitive customer. Price sensitive customers have the lowest relative levels of desires for conspicuous consumption and rarity while the price insensitive customers have the highest levels of these desires.

Figure 3 here. 


\section{Empirical Support for the Theory}

An elaborate laboratory market test by Hwang, Ko, and Megehee (2012) supports several of the nine key propositions. In a between-subjects experiment using photographs of four competing dress designs and four competing shoes — each with unique advertising message, Hwang, et al. (2012) varied conspicuous consumption and rarity at two levels each for one of the dresses and one of the shoes. Participants to their study included female students at a large national (South Korean) level university; the participants were recruited to participate while they were shopping in an on-campus shopping mall.

Here are the details of the manipulations of conspicuous consumption and rarity for the pair-of-treatment shoes following several rounds of pre-testing the quality of the treatment conditions. Low manipulated conspicuous consumption: "The designer making this shoe is not well-known but he is a qualified grandmaster." High manipulated conspicuous consumption: "Recognized world-wide for being handcrafted by a designer grandmaster." Low manipulated rarity: "1000 pairs were made including a pair that fit you perfectly." High manipulated rarity: “only 30 pairs were made, one of these 30 pairs fits you perfectly." The manipulated CC and rarity treatments for dresses were similar in content as the shoes' messages.

The two levels of CC and two levels of rarity were crossed with three levels of prices. The price for test treatment shoes were 50,000 Korean won (\$50), 200,000 won (\$200), 500,000 won (\$500). The prices for the treatment dress: 100,000 won $(\$ 100), 500,000$ won $(\$ 500)$, $1,000,000$ won $(\$ 1,000)$. Messages and prices for the remaining dresses and shoes were held constant in the experiment. Thus, the complete experiment includes 2 manipulations for CC, two 
for rarity, and three for prices for a total of 12 cells for dresses and 12 cells for shoes with 33 participants per cell $(\mathrm{n}=396$ total participants).

Each participant in the study was asked to select at least three of six items in a shopping trip for clothing appropriate for attending a friend's wedding — participants did not have to select any dress or any shoes on this virtual shopping trip. If the participant did select dresses (or shoes) "to buy today," she was asked to report the dress (shoes) she would most likely buy, her second choice, and her third choice. Thus, the researchers were able to report willing-to-buy scores (i.e., $4=$ first choice; $3=$ second choice; 2 = third choice; $1=$ fourth choice; $0=$ decision to buy a dress or shoes).

Following participating in the experiment, each participant completed appropriate scales to measure chronic desire-for-conspicuous consumption (Marcoux, Filiatrault, \& Cheron, 1997; Paurav, 2008) and chronic desire-for-rarity (Tian, Bearden, \& Hunter, 2001). For analyzing these chronic needs, Hwang et al. (2012) created quintile (5) groups from lowest, low, medium, high, and highest chronic need segments. Comparisons of price sensitivities to the lowest versus the highest chronic segment levels permit a clearer interpretation of influence of chronic conditions than median splits (Fitzsimons, 2008; McClelland, 1998).

Using confirmatory factor analysis, Hwang et al. (2012) identify two principal dimensions of $\mathrm{CC}$ rather than just one in their data: chronic desire-for-fame and chronic desireto-belong to a group. Both of these desires contributed separately to explaining choices for the treatment dresses and shoes.

Some key findings from Hwang et al.'s (2012) study for price influence choice for fame, belonging, and rarity chronic needs, and the manipulations of CC and rarity appear in Figures 4,5 , and 6 . While not matching the predictions of the theory perfectly, the findings include 
higher choices at all three prices for the conjunction of highest chronic need levels and manipulated CC and rarity treatments. The findings are consistent for the shoe treatments (not shown in the present article). In Figures 4, 5, 6, choice scores differences greater than 0.4 are significant statistically $(\mathrm{p}<.01)$.

Figures 4, 5, and 6 here.

Figure 7 illustrates the importance of segmenting customers by lowest to highest levels in chronic needs to provide sufficient sensitivities in the analyzing to learn the impact of such variables. Figure 7 shows a substantial interaction effect of increasing influence on choice for chronic desire for rarity for the high $(\boldsymbol{\Delta}=30 \%)$ versus low $(\boldsymbol{\Delta}=11 \%)$ manipulated rarity conditions. Thus, consumers vary in their responsiveness to rarity fashion marketing communications/designs according to their chronic levels of need for rarity.

Finally, Table 1 shows the findings of stepwise multiple regression analyses (MRA) to predict choice scores of the three treatment variables - the three chronic desire measures (i.e., fame, belonging, and rarity), and appropriate interactions among these variables for dresses. The stepwise solutions for dresses indicate that all three treatments and the chronic desire for belonging contribute significantly to explaining choice scores. The adjusted $\mathrm{R}^{2}(.181)$ indicates a highly-significant medium-effect size for the final stepwise model in explaining choice scores for the dress experiment.

Table 1 here. 
The findings for shoes appearing in Table 2 include a more complex and lower effect size explanation for choice scores but the findings are still insightful. Note that in both Table 1 and 2 that price is the first to enter into the MRA equations and all three manipulated variables contribute significantly in explaining choice.

Table 2 here.

For both the dress and shoes, one chronic or more chronic desire appears in the final stepwise solutions. The standardized beta weight $(\beta=.137)$ for chronic desire to belong is the same impact on choice score as the influence of manipulated rarity $(\beta=.137)$ and only slightly less than the influence of manipulated $C C(\beta=.179)$ for the dress experiment.

For shoes, a negative chronic desire for fame and rarity interaction term is significant in the final stepwise solution along with a positive interaction term for chronic desire for fame and belonging. This finding points out a complex relationship across the three chronic desires for shoes. The correlation for chronic desire-for-fame and choice scores for shoes is negative $(r=-$ $.095, \mathrm{p}<.065$, two-tailed test) while the correlation for chronic desire for belonging and choice scores for shoes is .025 (n.s.); for chronic desire for rarity and choice scores for shoes the correlation is positive $(\mathrm{r}=.092, \mathrm{p}<068$, two-tailed test $)$.

These findings support the conclusion that participants prefer to accomplish both fame•belonging while avoiding fame•rarity (the mid-level dot, "•", signifies the logical "and" connection. Attempting to solve such an intractable shopping dilemma may be the explanation for the long deliberation time by many women when shopping for shoes? 


\section{Discussion and Limitations}

The economic psychological and fashion marketing theory offers additional explanation, and nuance to Veblen's (1899) economic-sociological perspective on the influence of conspicuous consumption in his theory of the leisure class. The review of Hwang et al.'s (2012) experiment supports the theory revisions empirically.

The study offers an interesting application of interdisciplinary research that combines economics, fashion, marketing, and psychology. The theory and empirical findings support the view that the influence of fashion marketing designs and price depends substantially on the chronic desires of consumers and marketers' abilities to segment and target customers by these desires_a conclusion made explicit by Veblen (1899).

The intention is not to report that the theory and empirical review are conclusive. The study is limited in several ways. The theory does not cover social-economic status (SES) characteristics and the empirical study does not report on the influences of SES variables on choices. The empirical study is limited to participants in one university in one high-tech oriented country. Additional work in other cultures and elaborations of the theory would be useful. 


\section{References}

Berger, J., and Ward, M (2010). Subtle signals of inconspicuous consumption. Journal of Consumer Research, 37, 555-567.

Eskin, G. J. (1975). A case for test market experiments. Journal of Advertising Research, 15, 27-33.

Fitzsimons, Gavan J. (2008), “Death to dichotomizing,” Journal of Consumer Research, 35 (1), $5-8$.

Hwang, Y., Ko, E., and Megehee, C.M. (2012). The effects of conspicuous consumption, rarity, and price on consumer brand choice. Department of Fashion Marketing, Yonsei University, working paper.

Marcoux, J.-S., Filiatrault, P., and Cheron E. (1997). The attitudes underlying preferences of young urban educated polish consumers towards products made in western countries. Journal of International Consumer Marketing, 9, 5-29.

McClelland, D. C. (1998). Identifying competencies with behavioral-event interviews. Psychological Science, 9(5), 331-339.

Paurav, Shukla (2008). Status consumption in cross-national context: socio-psychological, brand and situational antecedents. International Marketing Review, 27 (1), 108-29.

Tian, K. T., Bearden, W.O., and Hunter, G. L. (2001). Consumers' need for uniqueness: scale development and validation. Journal of Consumer Research, 28, 50-66.

Veblen, Thorstein (1899), The theory of the leisure class. New York: Penguin. 


\section{Figure 1 \\ Discipline Interpretations of Brand and Price Relationships}

- Economics

- $\quad$ Marketing

- Psychology

- Fashion

- $\quad$ Economic psychology

- $\quad$ Fashion marketing
Price increases cause demand (choice) decreases for a brand.

Different customers respond differently to price increases; customers are classifiable (segmentable) by their chronic tendency to respond positively, negatively, or not at all to price increases.

Consumers implicitly (nonconsciously) assign higher quality to a product or brand with a high versus low price; consumers use price as an implicit marker for quality.

Price varies by brand logo visibility via an inverted "U" shape relationship so that moderately priced brands have the most visible logos.

Consumers' demand for brands with brand-visible logos varies by their chronic need for conspicuous consumption and income-consumers with very low and very high income exhibit less need for brand-visible logos.

Different price points (low, medium, and high) are nearly equally profitable for a fashion brand (e.g., Coach) for different designs of the brand planned by the firm for different customer segments. 


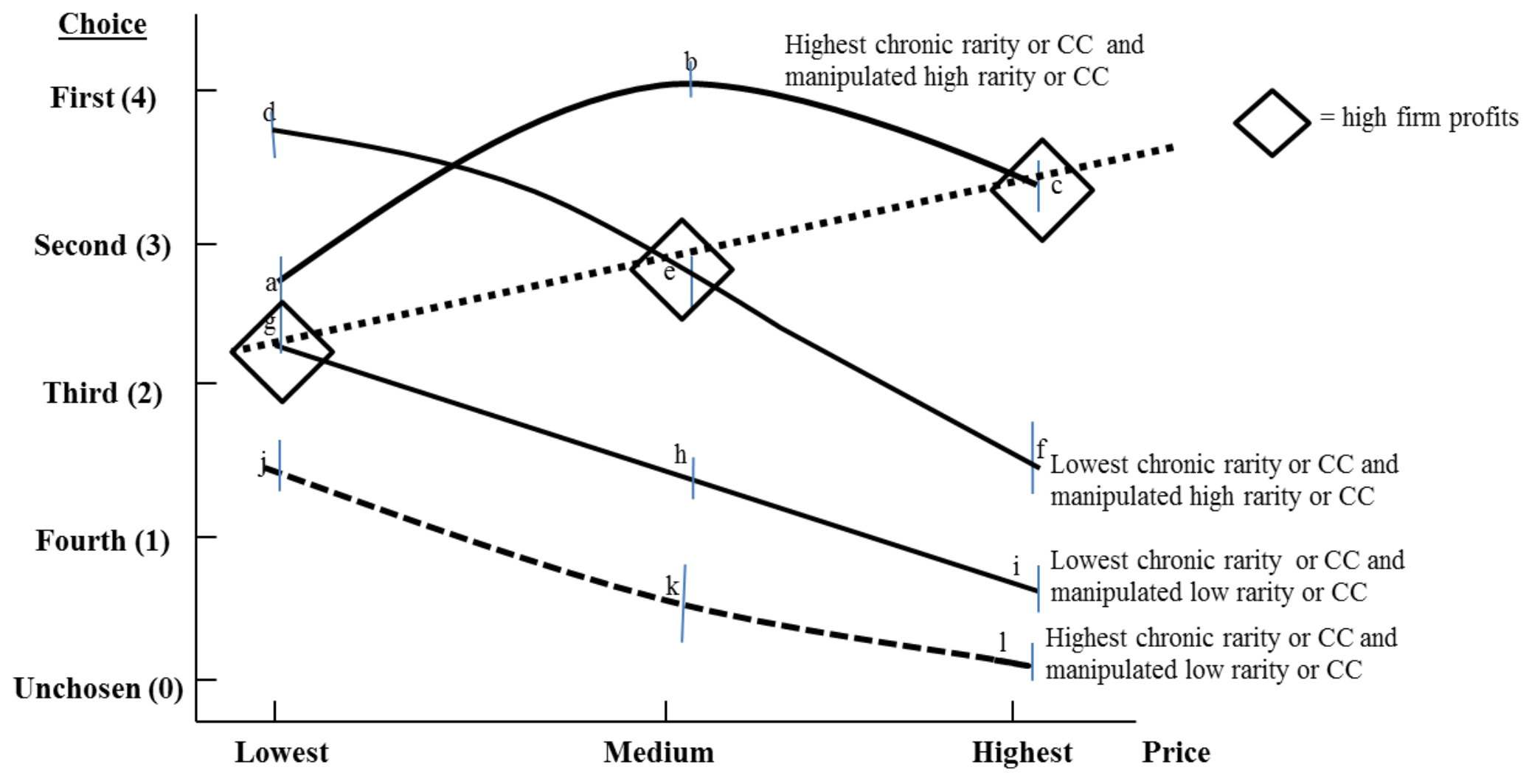

Figure 2

Price Influence on Choice among the Lowest and Highest Chronic Need for Rarity or Conspicuousness (CC) Groups 


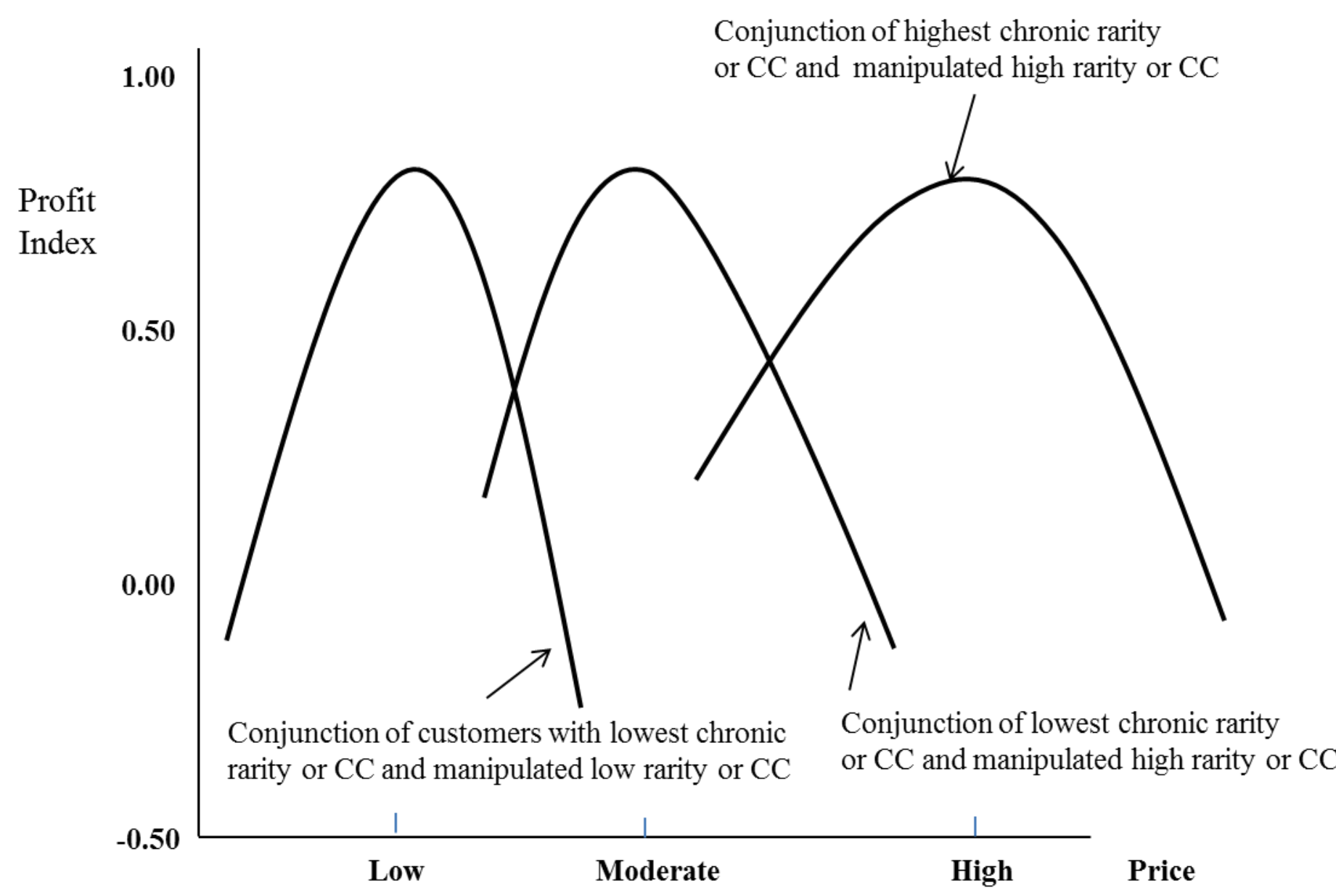

Figure 3

Profit Curves as a Function of Price and Conjunction of Customers with Varying Chronic Desires for Rarity and Manipulated Rarity or Conspicuous Consumption 


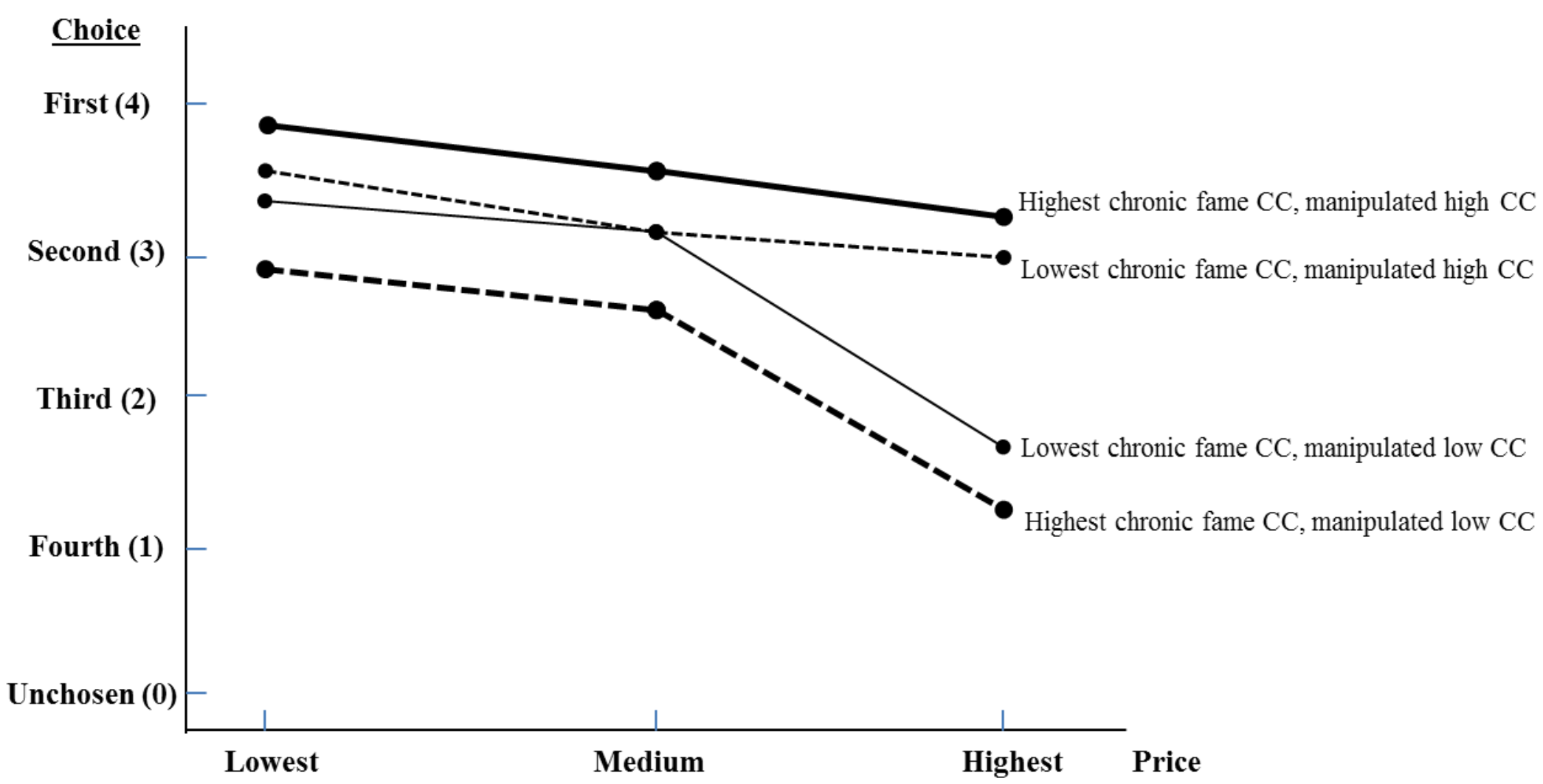

Figure 4

Chronic Conspicuousness (Fame) and Manipulated

Conspicuousness, Price, and Choice for Dress 


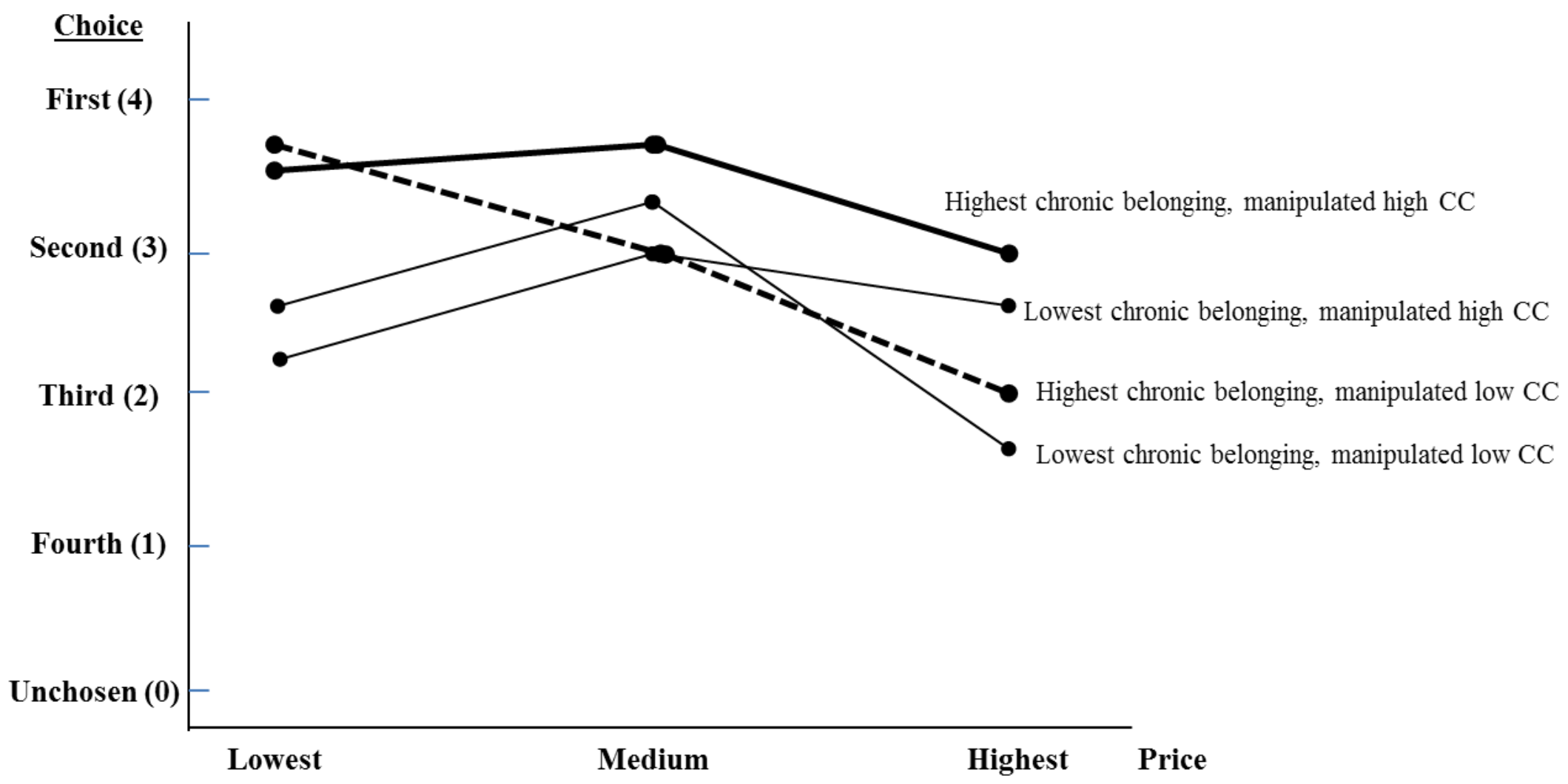

\section{Figure 5}

Chronic Conspicuousness (Belonging) and Manipulated Conspicuousness, Price, and Choice in the Dress Experiment 
Table 1

MRA Findings for Dress

Model Summary

\begin{tabular}{|l|l|r|r|r|}
\hline Model & $\mathrm{R}$ & R Square & \multicolumn{1}{c|}{$\begin{array}{c}\text { Adjusted R } \\
\text { Square }\end{array}$} & $\begin{array}{c}\text { Std. Error of } \\
\text { the Estimate }\end{array}$ \\
\hline 1 & $.346^{\mathrm{a}}$ & .120 & .118 & 1.20063 \\
2 & $.391^{\mathrm{b}}$ & .153 & .149 & 1.17932 \\
3 & $.413^{\mathrm{c}}$ & .170 & .164 & 1.16883 \\
4 & $.435^{\mathrm{d}}$ & .189 & .181 & 1.15705 \\
\hline
\end{tabular}

a. Predictors: (Constant), dress_price

b. Predictors: (Constant), dress_price. dress_conspicuousness

c. Predictors: (Constant), dress_price,

dress conspicuousness, belonging desire

d. Predictors: (Constant), dress price

dress_conspicuousness, belonging desire, dress_rarity
Coefficients $^{a}$

\begin{tabular}{|c|c|c|c|c|c|c|}
\hline \multirow{2}{*}{\multicolumn{2}{|c|}{ Model }} & \multicolumn{2}{|c|}{ Unstandardized Coefficients } & \multirow{2}{*}{$\begin{array}{c}\begin{array}{c}\text { Standardized } \\
\text { Coefficients }\end{array} \\
\text { Beta }\end{array}$} & \multirow[b]{2}{*}{$\mathrm{t}$} & \multirow[b]{2}{*}{ Sig. } \\
\hline & & $\mathrm{B}$ & Std. Error & & & \\
\hline \multirow[t]{2}{*}{1} & (Constant) & 3.891 & .160 & & 24.378 & .000 \\
\hline & dress_price & -.542 & .074 & -.346 & -7.330 & .000 \\
\hline \multirow[t]{3}{*}{2} & (Constant) & 3.194 & .237 & & 13.476 & .000 \\
\hline & dress_price & -.542 & .073 & -.346 & -7.463 & .000 \\
\hline & dress_conspicuousness & .465 & .119 & .182 & 3.920 & .000 \\
\hline \multirow[t]{4}{*}{3} & (Constant) & 2.874 & .261 & & 11.025 & .000 \\
\hline & dress_price & -.544 & .072 & -.348 & -7.559 & .000 \\
\hline & dress_conspicuousness & .458 & .117 & .179 & 3.901 & .000 \\
\hline & belonging desire & .114 & .040 & .131 & 2.844 & .005 \\
\hline \multirow[t]{5}{*}{4} & (Constant) & 2.333 & .315 & & 7.419 & .000 \\
\hline & dress_price & -.544 & .071 & -.348 & -7.638 & .000 \\
\hline & dress_conspicuousness & .458 & .116 & .179 & 3.938 & .000 \\
\hline & belonging desire & .120 & .040 & .137 & 3.010 & .003 \\
\hline & dress_rarity & .350 & .116 & .137 & 3.004 & .003 \\
\hline
\end{tabular}

a. Dependent Variable: Dress_depend2 
Table 2

MRA Findings for Shoes

Model Summary

\begin{tabular}{|c|c|r|r|r|}
\hline Model & $\mathrm{R}$ & $\mathrm{R}$ Square & $\begin{array}{c}\text { Adjusted R } \\
\text { Square }\end{array}$ & $\begin{array}{c}\text { Std. Error of } \\
\text { the Estimate }\end{array}$ \\
\hline 1 & $.201^{\mathrm{a}}$ & .040 & .038 & 1.19644 \\
2 & $.271^{\mathrm{b}}$ & .074 & .069 & 1.17696 \\
3 & $.285^{\mathrm{C}}$ & .081 & .074 & 1.17374 \\
4 & $.316^{\mathrm{d}}$ & .100 & .091 & 1.16312 \\
5 & $.330^{\mathrm{e}}$ & .109 & .097 & 1.15888 \\
\hline
\end{tabular}

a. Predictors: (Constant), shoes_price

b. Predictors: (Constant), shoes_price, rarity_s_conspic_s

c. Predictors: (Constant), shoes_price, rarity_s_conspic_s, rarity chronic groups

d. Predictors: (Constant), shoes_price, rarity_s_conspic_s, rarity chronic groups, fame_rarity_grp

e. Predictors: (Constant), shoes_price, rarity_s_conspic_s, rarity chronic groups, fame_rarity_grp, fame_bēlong

Note. The impact of CC on choice is nuanced. Chronic fame and rare shoes is a positive influence; chronic fame and desire for rarity is a negative influence; chronic belonging is a positive influence.
Coefficients $^{a}$

\begin{tabular}{|c|c|c|c|c|c|c|}
\hline \multirow{2}{*}{\multicolumn{2}{|c|}{ Model }} & \multicolumn{2}{|c|}{ Unstandardized Coefficients } & \multirow{2}{*}{$\begin{array}{c}\text { Standardized } \\
\text { Coefficients } \\
\text { Beta }\end{array}$} & \multirow[b]{2}{*}{$t$} & \multirow[b]{2}{*}{ Sig. } \\
\hline & & $B$ & Std. Error & & & \\
\hline \multirow[t]{2}{*}{1} & (Constant) & 3.235 & .159 & & 20.336 & .000 \\
\hline & shoes_price & -.299 & .074 & -.201 & -4.064 & .000 \\
\hline \multirow[t]{3}{*}{2} & (Constant) & 2.776 & .198 & & 13.983 & .000 \\
\hline & shoes_price & -.299 & .072 & -.201 & -4.131 & .000 \\
\hline & rarity_s_conspic_s & .204 & .054 & .183 & 3.761 & .000 \\
\hline \multirow[t]{4}{*}{3} & (Constant) & 2.543 & .237 & & 10.724 & .000 \\
\hline & shoes_price & -.295 & .072 & -.198 & -4.078 & .000 \\
\hline & rarity_s_conspic_s & .205 & .054 & .183 & 3.784 & .000 \\
\hline & rarity chronic groups & .074 & .042 & .086 & 1.777 & .076 \\
\hline \multirow[t]{5}{*}{4} & (Constant) & 2.507 & .235 & & 10.653 & .000 \\
\hline & shoes_price & -.288 & .072 & -.193 & -4.023 & .000 \\
\hline & rarity_s_conspic_s & .209 & .054 & .187 & 3.891 & .000 \\
\hline & rarity chronic groups & .190 & .058 & .220 & 3.282 & .001 \\
\hline & fame_rarity_grp & -.037 & .013 & -.192 & -2.862 & .004 \\
\hline \multirow[t]{6}{*}{5} & (Constant) & 2.335 & .250 & & 9.324 & .000 \\
\hline & shoes_price & -.301 & .072 & -.202 & -4.203 & .000 \\
\hline & rarity_s_conspic_s & .213 & .053 & .190 & 3.974 & .000 \\
\hline & rarity chronic groups & .251 & .065 & .291 & 3.833 & .000 \\
\hline & fame_rarity_grp & -.058 & .017 & -.304 & -3.463 & .001 \\
\hline & fame_belong & .022 & .011 & .124 & 1.967 & .050 \\
\hline
\end{tabular}

a. Dependent Variable: Shoes Depend2 